\title{
Self-Assembled Monolayers of Symmetrical and Mixed Alkyl Fluoroalkyl Disulfides on Gold. 2. Investigation of Thermal Stability and Phase Separation
}

\author{
H. Schönherr, ${ }^{*}, \dagger$ H. Ringsdorf, ${ }^{\dagger} M$ M. J aschke, ${ }^{\ddagger}$ H.-J . Butt, ${ }^{\ddagger}$ E. Bamberg, ${ }^{\ddagger}$ \\ H. Allinson, ${ }^{\S}$ and S. D. Evans ${ }^{\S}$
}

Institut für Organische Chemie J . Gutenberg-U niversität, D-55099 Mainz, Germany, Max-Planck-I nstitut für Biophysik, Kennedyalle 70, D-60596 Frankfurt/ Main, Germany, and Department of Physics, University of Leeds, Leeds LS2 9J T, United Kingdom

Received February 15, 1996. In Final Form: May 17, $1996^{\otimes}$

\begin{abstract}
The investigation of the thermal stability of self-assembled monolayers of symmetrical and mixed alkyl fluoroalkyl disulfides on gold is reported. The monolayers were annealed in air at temperatures ranging from 60 to $110^{\circ} \mathrm{C}$ for several hours and afterward characterized by contact angle measurements, polarized grazing incidenceF ourier transform infrared spectroscopy (FTIR), X-ray photoelectron spectroscopy (XPS), and atomic force mi croscopy (AFM). In mixed al kyl perfluoroalkyl systems evidence was sought for heatinduced phase separation of the alkyl- and perfluoroalkyl-terminated molecules. The ester and amide linkages of the fluorocarbon chains are shown to be less stable than those of the hydrocarbon anal ogues. Fluorosubstituents in $\alpha$-positi on totheester linkage maketheester bond susceptibletohydrolyticcleavage at temperatures between 60 and $70^{\circ} \mathrm{C}$, whereas the corresponding amide and the $\gamma$-fluoro-substituted esters remain stable up to $80-100^{\circ} \mathrm{C}$. After annealing for $10 \mathrm{~h}$ or longer at these temperatures contact angl emeasurements, XPS, and FTI R reveal partial loss of fluorocarbon chai ins in monolayers of symmetrical fluoroalkyl disulfides and mixed alkyl fluoroalkyl disulfides. In contrast, it is still possible to observe ordered domains with AFM in monolayers of mixed alkyl fluoroalkyl disulfides annealed at $100^{\circ} \mathrm{C}$ for 17 h. AFM scans in molecular resolution confirm that the lattice constant of the hexagonal lattice remains unchanged $(6.2 \AA)$. Since the monol ayers of both corresponding symmetrical disulfides show significantly smaller latticeconstants, heat-induced phaseseparation can beexcluded. Theresults indicatenonexisting to very low mobility of the molecules within thelayer at higher temperatures. Alternatively, the existence of disulfides rather than thiolates bound to the gold can explain the observations.
\end{abstract}

\section{Introduction}

Understanding and controlling theproperties of surfaces and interfaces are of tremendous importance in many kinds of technical applications. Well-organized model systems likeself-assembled monolayers (SAMs) of organic molecules on various substrates are therefore of widespread interest. ${ }^{1,2}$ SAMs of thiols, ${ }^{3}$ disulfides, ${ }^{4}$ or thioethers ${ }^{5}$ on gold are one class of thoroughly investigated systems. Theinterest is certainly not limited to themodel role of SAMs as model s for organic surfaces and interfaces in general. ${ }^{6}$ The ease of preparation together with the high degree of order on the molecular level makes these systems attractivefor novel applications such as molecular recognition and sensors ${ }^{7-10}$ or patterning and nanolithography. ${ }^{11,12}$

* Correspondence address: University of Twente, Chemical Technology, PMT, P.O. Box 217, 7500 AE Enschede, The Netherlands. Fax: $(++31) 534893823$. E-mail: H.SCHONHERR@CT. UTWENTE.NL.

${ }^{\dagger}$. Gutenberg-Universität.

₹ Max-Planck-Institut für Biophysik.

$\S$ University of Leeds.

${ }^{\otimes}$ Abstract published in Advance ACS Abstracts, J uly 1, 1996.

(1) UIman, A. Introduction to Ultrathin Films, from Langmuir-

Blodgett Films to Self-Assembly; Academic Press: Boston, MA 1991.

(2) Dubois, L. H.; Nuzzo, R. G. Annu. Rev. Phys. Chem. 1992, 43, 437.

(3) Nuzzo, R. G.; Zegarski, B. R.; Dubois, L. H. J . Am. Chem. Soc. 1987, 109, 733.

(4) Nuzzo, R. G.; Allara, D. L. J . Am. Chem. Soc. 1983, 105, 4481. (5) Troughton, E. B.; Bain, C. D.; Whitesides, G. M.; Nuzzo, R. G.; Allara, D. L.; Porter, M. D. Langmuir 1988, 4, 365.

(6) Bain, C. D.; Whitesides, G. M. Adv. Mater. 1989, 1, 110.

(7) Spinke, J .; Liley, M.; Schmitt, F.-J .; Guder, H.-J .; Angermaier,

L.; Knoll, W. J . Chem. Phys. 1993, 99, 7012.

(8) Turyan, I.; Mandler, D. Anal. Chem. 1994, 66, 58.

(9) Thoden van Velzen, E. U.; Engbersen, J . F. J .; Reinhoudt, D. N.

J . Am. Chem. Soc. 1994, 116, 3597.

(10) Rojas, M. T.; Kaifer, A. E. J . Am. Chem. Soc. 1995, 117, 5883.
In this paper wereport theattempt toachievepatterned surfaces of SAM s of mixed alkyl fluoroalkyl disulfides on gold by heat-induced phaseseparation intomonodomains on the surface. In contrast to coadsorption experiments from solutions containing mixtures of thiols, this would lead to systems which are at least close to thermodynamical equilibrium. With suitable $\omega$-functionalized molecules chemistry could bedonehighly local ized within these domains. In combination with other patterning techniques a series of reactors with different functional groups or recognition units could be placed in a predetermined way on the surface.

The motivation for this study was partly to create patterns on the surface of SAMs in the nanometer size regime. In addition, thereis somebasicinterest involved. The nature of the mol ecular species actually bound to the gold has not been determined unequivocally. The molecules of SAMs derived from thiols and corresponding disulfides were shown to be identical by X-ray photoelectron spectroscopy (XPS). ${ }^{13}$ Time of flight secondary ion mass spectrometry (TOF-SIMS) ${ }^{14}$ on SAMs of thiols and disulfides as well as exchange experiments of mixed disul fides ${ }^{15}$ suggested strongly that thiols and disulfides bind as thiolates to the gold. In Figure 1 the previously accepted reaction scheme is shown. Recently, the existence of a disulfiderather than a thiolate bound to the gold has been postulated on the basis of X-ray diffraction investigations. ${ }^{16}$

(11) Tarlov, M. J .; Burgess D. R. F., J r.; Gillen, G. J . Am. Chem. Soc. 1993, 115, 5305.

(12) Gorman, C. B.; Biebuyck, H. A.; Whitesides, G. M. Chem. Mater. $1995,7,526$ and references therein.

(13) Biebuyck, H. A.; Bain, C. D.; Whitesides, G. M. Langmuir 1994 10,1825

(14) Hagenhoff, B.; Benninghoven, A.; Spinke, J .; Liley, M.; Knoll, W. Langmuir 1993, 9, 1622.

(15) Biebuyck, H. A.; Whitesides, G. M. Langmuir 1993, 9, 1766. 


$$
2 \mathrm{CH}_{3}-\left(\mathrm{CH}_{2}\right)_{\bar{n}} \mathrm{SH} \quad \begin{aligned}
& \mathrm{S}-\left(\mathrm{CH}_{2}\right)_{\overline{\mathrm{n}}}-\mathrm{CH}_{3} \\
& \mathrm{~S}-\left(\mathrm{CH}_{2}\right)_{\overline{\mathrm{n}}}-\mathrm{CH}_{3}
\end{aligned}
$$<smiles>CCCCC</smiles>

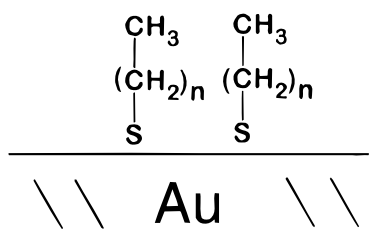

Figure 1. Widely accepted reaction scheme for the reaction of alkanethiols and alkyl disulfides with the gold surface in the process of monolayer formation.
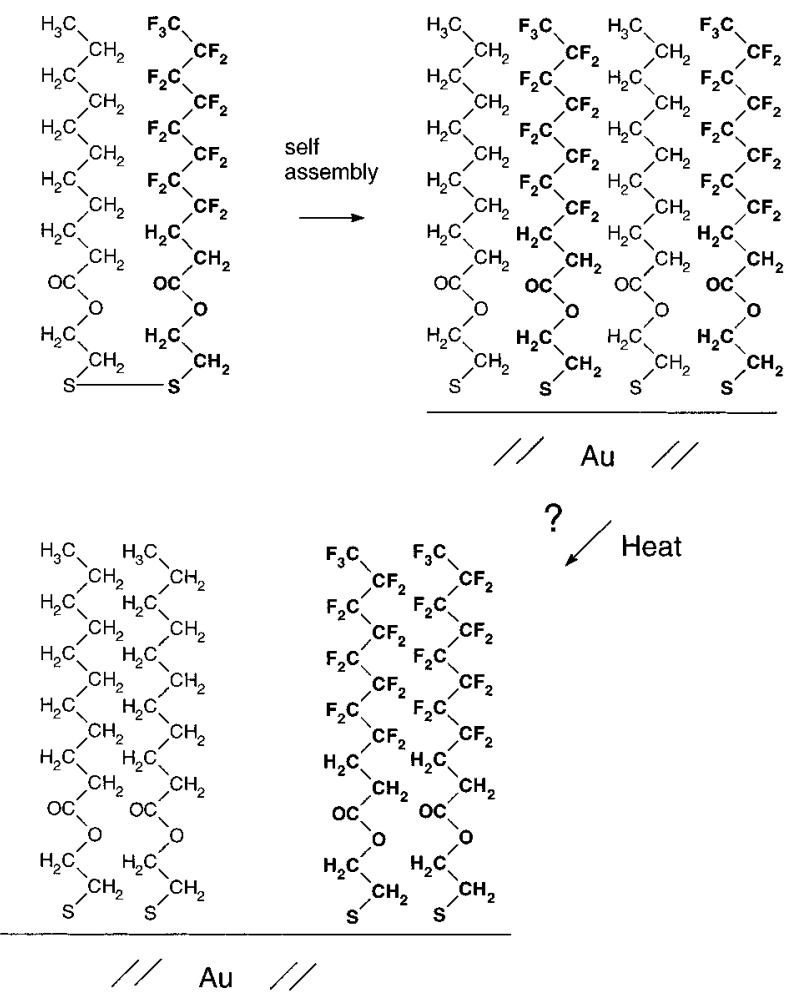

Figure 2. Possible scenario of self-assembly and subsequent heat-induced phase separation into monodomains of SAMs of 13 on the gold surface.

The thermal stability of SAMs of thiols has also been the subject of previous studies. ${ }^{17,18}$ Annealing at temperatures below $100{ }^{\circ} \mathrm{C}$ leads to an improved molecular order of theSAMs. ${ }^{9}$ Themorphology of the gold substrate (gold(111)) is altered as well. Annealing leads to the coalescense of the typical etch pits in the gold. ${ }^{19,20}$

As depicted in Figure 2, we investigated whether it is possible to promote mobility of the molecules in the SAM

(16) Fenter, P.; Eberhardt, A.; Eisenberger, P. Science 1994, 226, 1216.

(17) (a) Delamarche, E.; Michel, B.; Kang, H.; Gerber, Ch. Langmuir 1994, 10, 4103. (b) Schönenberger, C.;J orritsma, J .; Sondag-Huethorst, J. A. M.; Fokkink, L. G. J. Phys. Chem. 1995, 99, 3259.

(18) Delamarche, E.; Michel, B.; Gerber, Ch.; Anselmetti, D.; Güntherodt, H.-J .; Wolf, H.; Ringsdorf, H. Langmuir 1994, 10, 2869.

(19) Schönenberger, C.; Sondag-Huethorst, J. A. M.; J orritsma, J .; Fokkink, L. G. Langmuir 1994, 10, 611.

(20) Stranick, S.J .; Parikh, A. N.; Allara, D. L.; Weiss, P. S. J . Phys. Chem. 1994, 98, 11136. by lowering the interaction between neighboring chains. The interaction between alkyl and perfluoroalkyl chains is lower than that between alkyl chains, or perfluoroalkyl chains, respectively. In other highly ordered systems like li posomes ${ }^{21}$ and Langmuir-B lodgett films, ${ }^{22}$ this leads to phase separation in mixed alkyl perfluoroalkyl systems. Even at room temperature phase separation could be demonstrated in these cases. At roomtemperaturemixed alkyl perfluoroalkyl disulfides form SAMs on Au(111) with a unique lattice compared to the corresponding symmetrical disulfides. This could be proven by atomic force microscopy (AFM). ${ }^{23}$ Thus, the molecules are not mobile at room temperature since no phase separation was observed. Given that the mobility of the thiolates is high enough at temperatures bel ow which desorption becomes competitive, phase separation into monodomains should be feasible. A simulation ${ }^{24}$ as well as a thermodynamical treatment of a possible phase separation in monolayers ${ }^{25}$ suggest theformation of monodomains in thecase of mobile molecules. Since phase separation would require independent behavior of the two parts of the molecule, this would unequivocally prove the cleavage of the sulfursulfur bond of the disulfide in the reaction with the gold and the existence of thiolates on the gold surface.

In order totest theapproach weinvestigated thethermal stability of SAMs on gold of three homologous series of mixed alkyl fluoroalkyl disulfides together with the corresponding symmetrical disulfides. The synthesis of thecompounds and themonolayer properties of thefreshly prepared SAMs have been reported earlier.23,26 After annealing in air, the SAM s were probed by contact angle, grazing incidence polarized Fourier transform infrared (FTIR), XPS, and AFM measurements.

\section{Experimental Part}

Preparation of Substrates. Gold substrates for contact angle measurements and FTIR studies were prepared by evaporation of approximately $3 \mathrm{~nm}$ of chromium followed by 120 $\mathrm{nm}$ of gold onto cleaned glass slides ${ }^{26}$ in a vacuum of $5 \times 10^{-6}$ mbar in a Balzer evaporation machine. For the XPS measure ments silicon wafers were used instead of glass substrates. ${ }^{27}$ $A u(111)$ substrates for AFM experiments were prepared by evaporation of gold onto freshly cleaved mica sheets followed by annealing and subsequent quenching to room temperature. The exact procedure has been published before. ${ }^{23,28}$

Preparation of Monolayers. Monolayers were formed by immersing the gold substrates into a dilute solution (1.0 to 5.0 $\times 10^{-4} \mathrm{M}$ ) of the corresponding compound in methylenechloride. After incubation of $\mathbf{2 4} \mathrm{h}$ or longer, the samples were removed from the solution, rinsed car efully with pure solvent, and dried in a nitrogen stream.

Annealing in Air. After initial characterization the substrates covered with monolayers were placed on a metal grid in a preheated Heraeus oven at a given temperature. After annealing the SAMs were allowed to cool down to room temperature in a sealed glass container.

Contact Angle Measurements. Theadvancing and receding contact angles $\theta_{\mathrm{a}}$ and $\theta_{\mathrm{r}}$ were measured with Millipore water as

(21) Elbert, R.; Folda, T.; Ringsdorf, H.J . Am. Chem. Soc. 1984, 106, 7687.

(22) Overney, R. M.; Meyer, E.; Frommer, J .; Brodbeck, D.; Lüthi, R.; Howald, L.; Güntherodt, H.-J .; Fujihira, M.; Takano, H.; Gotoh, Y. Nature 1992, 359, 133.

(23) J aschke, M.; Schönherr, H.; Wolf, H.; Ringsdorf, H.; Besocke, M. K.; Bamberg, E.; Butt, H.-J . J . Phys. Chem. 1996, 100, 2290.

(24) Siepmann, J . I.; McDonald, I. R. Mol. Phys. 1992, 75, 255.

(25) Folkers, J . P.; Laibinis, P. E.; Whitesides, G. M. J . Phys. Chem. 1994, 98, 563.

(26) Schönherr, H.; Ringsdorf, H. Langmuir, in press

(27) Batchelder, D. N.; Evans, S. D.; Freeman, T. L.; Häussling, L. Ringsdorf, H.; Wolf, H. J . Am. Chem. Soc. 1994, 116, 1050.

(28) Wolf, H.; Ringsdorf, H.; Delamarche, E.; Takami, T.; Kang, H.; Michel, B.; Gerber, Ch.; J aschke, M.; Butt, H.-J .; Bamberg, E.J . Phys. Chem. 1995, 99, 7102. 


$$
\begin{aligned}
& \mathrm{S}-\mathrm{CH}_{2}-\mathrm{CH}_{2} \mathrm{O}-\mathrm{CO}-\left(\mathrm{CH}_{2}\right)_{\mathrm{n}}-\mathrm{CH}_{3} \\
& \mathrm{~S}-\mathrm{CH}_{2}-\mathrm{CH}_{2} \mathrm{O}-\mathrm{CO}-\left(\mathrm{CH}_{2}\right)_{\overline{\mathrm{n}}}-\mathrm{CH}_{3} \\
& \mathrm{I}(\mathrm{n}=10), 2(\mathrm{n}=16), 3(\mathrm{n}=20) \\
& \mathrm{S}-\mathrm{CH}_{2}-\mathrm{CH}_{2} \mathrm{O}-\mathrm{CO}-\left(\mathrm{CF}_{2}\right)_{8}-\mathrm{CF}_{3} \\
& \mathrm{~S}-\mathrm{CH}_{2}-\mathrm{CH}_{2} \mathrm{O}-\mathrm{CO}-\left(\mathrm{CF}_{2}\right)_{8}-\mathrm{CF}_{3} \\
& 4 \\
& \mathrm{~S}-\mathrm{CH}_{2}-\mathrm{CH}_{2} \mathrm{O}-\mathrm{CO}-\left(\mathrm{CH}_{2}\right)_{2}-\left(\mathrm{CF}_{2}\right)_{7}-\mathrm{CF}_{3} \\
& \mathrm{~S}-\mathrm{CH}_{2}-\mathrm{CH}_{2} \mathrm{O}-\mathrm{CO}-\left(\mathrm{CH}_{2}\right)_{2}-\left(\mathrm{CF}_{2}\right)_{7}-\mathrm{CF}_{3}
\end{aligned}
$$

5<smiles>CCSSCCCOC(=O)CCCOC(=O)CCC(C(F)(F)F)C(F)(F)F</smiles>

6

$\mathrm{S}-\mathrm{CH}_{2}-\mathrm{CH}_{2} \mathrm{O}-\mathrm{CO}-\left(\mathrm{CF}_{2}\right)_{8}-\mathrm{CF}_{3}$
$\mathrm{~S}-\mathrm{CH}_{2}-\mathrm{CH}_{2}-\mathrm{O}-\mathrm{CO}-\left(\mathrm{CH}_{2}\right)_{\mathrm{n}}-\mathrm{CH}_{3}$

$7(\mathrm{n}=6), 8(8), 9(10), 10(12), 11(14)$,

$12(\mathrm{n}=16)$

$\mathrm{S}-\mathrm{CH}_{2}-\mathrm{CH}_{2} \mathrm{O}-\mathrm{CO}-\left(\mathrm{CH}_{2}\right)_{2}-\left(\mathrm{CF}_{2}\right)_{7}-\mathrm{CF}_{3}$
$\mathrm{~S}-\mathrm{CH}_{2}-\mathrm{CH}_{2} \mathrm{O}-\mathrm{CO}-\left(\mathrm{CH}_{2}\right)_{\bar{n}}-\mathrm{CH}_{3}$

$13(\mathrm{n}=9), 14(10), 15(12), 16(14), 17(16)$<smiles>CCCCCCC(OC(=O)NCCSSC)(C(F)(F)F)C(F)(F)F</smiles>

$18(\mathrm{n}=11), 19(15), 20(17)$

$\mathrm{HS}-\mathrm{CH}_{2}-\mathrm{CH}_{2}-\mathrm{NH}-\mathrm{CO}-\left(\mathrm{CF}_{2}\right)_{7}-\mathrm{CF}_{3}$

21

Figure 3. Investigated compounds and their abbreviations.

a probe liquid on a contact angle microscope (G-1, Krüss, Hamburg). Details can be found in ref 26. The hysteresis was calculated as $-(\Delta \cos \theta)$.

Polarized Fourier Transform Infrared Spectroscopy (FTIR) in Grazing Incidence. The IR data were obtained on a Nicolet 5DXC FTIR spectrometer which was equipped with a FT80 specular reflectance setup (Spectratech Inc.). For details see ref 26.

X-ray Photoelectron Spectroscopy (XPS). The XPS spectra were obtained on a Scienta ESCA 300 Instrument. A high-intensity, $2.8 \mathrm{~kW}$, monochromatic Al K $\alpha(\mathrm{h} v=1486.6 \mathrm{eV})$ radiation source was used and the analyzer slit width and pass energy were set to $0.8 \mathrm{~mm}$ and $150 \mathrm{eV}$, respectively. Spectra were obtained for electron take-off angles of $10^{\circ}$ (grazing) and $90^{\circ}$ (normal), with the base pressure in the sample chamber maintained at $10^{-9}$ Torr. Unless otherwise stated the data presented here refer to those obtained at $10^{\circ}$.

Atomic F orce Microscopy (AF M). TheAF M measurements wereperformed with a NanoScopel II AFM (Digital Instruments) using a liquid cell filled with ethanol. Sharpened tips (Olympus Tokio, $0.09 \mathrm{~N} / \mathrm{m}$ spring constant) were used for theinvestigations which were done in contact mode. All the images shown are raw data which were planefitted. The force between tip and sample was typically $1 \mathrm{nN}$.

\section{Results and Discussion}

The freshly prepared monol ayers of all the compounds listed in Figure 3 were investigated by means of contact
Table 1. Contact Angles $\left(\mathrm{H}_{2} \mathrm{O}\right)$ of Annealed SAMs of Symmetrical Disulfides (1-6)

\begin{tabular}{clcrc}
\hline compound & conditions $^{\mathrm{a}}$ & $\theta_{\mathrm{a}}$, deg & $\theta_{\mathrm{r}}$, deg & hysteresis \\
\hline $\mathbf{1}$ & as prepared & 106 & 96 & 0.171 \\
& $48 \mathrm{~h}, 80^{\circ} \mathrm{C}$ & 106 & 95 & 0.188 \\
\multirow{2}{*}{$\mathbf{2}$} & $24 \mathrm{~h}, 100^{\circ} \mathrm{C}$ & 106 & 91 & 0.258 \\
& as prepared & 108 & 101 & 0.118 \\
& $14 \mathrm{~h}, 80^{\circ} \mathrm{C}$ & 108 & 100 & 0.135 \\
$\mathbf{4}$ & $21 \mathrm{~h}, 100^{\circ} \mathrm{C}$ & 103 & 94 & 0.155 \\
& as prepared $^{2}$ & 116 & 109 & 0.113 \\
$\mathbf{5}$ & $19 \mathrm{~h}, 80^{\circ} \mathrm{C}$ & 104 & 95 & 0.155 \\
& as prepared & 116 & 107 & 0.146 \\
$\mathbf{6}$ & $11 \mathrm{~h}, 80^{\circ} \mathrm{C}$ & 115 & 106 & 0.147 \\
& as prepared & 117 & 107 & 0.162 \\
& $24 \mathrm{~h}, 100^{\circ} \mathrm{C}$ & 117 & 106 & 0.178
\end{tabular}

a Selected examples of different annealing experiments were chosen in order to give a general overview.

Table 2. Contact Angles $\left(\mathrm{H}_{2} \mathrm{O}\right)$ of Annealed SAMs of 18

\begin{tabular}{lccc}
\hline conditions $^{\mathrm{a}}$ & $\theta_{\mathrm{a}}$, deg & $\theta_{\mathrm{r}}$, deg & hysteresis \\
\hline as prepared & 114 & 107 & 0.114 \\
$20 \mathrm{~h}, 80^{\circ} \mathrm{C}$ & 113 & 105 & 0.132 \\
$20 \mathrm{~h}, 100^{\circ} \mathrm{C}$ & 108 & 98 & 0.170 \\
$20 \mathrm{~h}, 120^{\circ} \mathrm{C}$ & 102 & 81 & 0.364
\end{tabular}

a Selected examples of different annealing experiments were chosen in order to give a general overview.

Table 3. Contact Angles $\left(\mathrm{H}_{2} \mathrm{O}\right)$ of Annealed SAMs of $\mathbf{9}$

\begin{tabular}{lccc}
\hline conditions $^{\mathrm{a}}$ & $\theta_{\mathrm{a}}$, deg & $\theta_{\mathrm{r}}$, deg & hysteresis \\
\hline as prepared & 112 & 104 & 0.133 \\
$73 \mathrm{~h}, 60^{\circ} \mathrm{C}$ & 112 & 103 & 0.150 \\
$43 \mathrm{~h}, 70^{\circ} \mathrm{C}$ & 103 & 92 & 0.196 \\
$24 \mathrm{~h}, 80^{\circ} \mathrm{C}$ & 103 & 86 & 0.295
\end{tabular}

a Selected examples of different annealing experiments were chosen in order to give a general overview.

Table 4

(a) Contact Angles $\left(\mathrm{H}_{2} \mathrm{O}\right)$ of Annealed SAMs of $\mathbf{1 3}$

\begin{tabular}{lccc}
\hline conditions $^{\mathrm{a}}$ & $\theta_{\mathrm{a}}$, deg & $\theta_{\mathrm{r}}$, deg & hysteresis \\
\hline as prepared & 113 & 104 & 0.149 \\
$73 \mathrm{~h}, 60^{\circ} \mathrm{C}$ & 113 & 102 & 0.183 \\
$43 \mathrm{~h}, 70^{\circ} \mathrm{C}$ & 113 & 104 & 0.149 \\
$24 \mathrm{~h}, 80^{\circ} \mathrm{C}$ & 113 & 101 & 0.200 \\
$20 \mathrm{~h}, 100^{\circ} \mathrm{C}$ & 113 & 101 & 0.200
\end{tabular}

(b) Contact Angles $\left(\mathrm{H}_{2} \mathrm{O}\right)$ of Annealed SAMs of 13-17

\begin{tabular}{ccccc}
\hline compound & conditions $^{\mathrm{a}}$ & $\theta_{\mathrm{a}}$, deg & $\theta_{\mathrm{r}}$, deg & hysteresis \\
\hline \multirow{1}{13}{} & as prepared & 113 & 104 & 0.149 \\
& $14 \mathrm{~h}, 100^{\circ} \mathrm{C}$ & 113 & 102 & 0.183 \\
$\mathbf{1 4}$ & as prepared & 112 & 102 & 0.167 \\
& $14 \mathrm{~h}, 100^{\circ} \mathrm{C}$ & 110 & 100 & 0.168 \\
$\mathbf{1 6}$ & as prepared & 112 & 103 & 0.150 \\
& $14 \mathrm{~h}, 100^{\circ} \mathrm{C}$ & 112 & 101 & 0.184 \\
$\mathbf{1 7}$ & as prepared & 111 & 100 & 0.185 \\
& $14 \mathrm{~h}, 100^{\circ} \mathrm{C}$ & 111 & 100 & 0.185
\end{tabular}

a Selected examples of different annealing experiments were chosen in order to give a general overview.

angle measurements and grazing incidence FTIR spectroscopy prior to further annealing experiments. The properties observed for a large number of samples have been published before. ${ }^{26}$

The contact angles give a first hint as to monolayer stability in air at higher temperatures. The values observed are listed in Tables 1 -4. Compared to thermal stabilities published in literature beforefor $n$-alkanethiols, we can confirm a threshold for desorption for comparable SAMs of roughly $100^{\circ} \mathrm{C}$. Exception are only found for SAM s of activated esters of perfluorinated carboxylicacids like compound 4 and the mixed disulfides 7-12. Here 
the hydrolysis of the ester seems to set in before the desorption starts.

Before dealing with the more complicated mixed al kyl fluoroalkyl systems, we want to discuss the symmetric ones. The SAMs derived from symmetrical bis(alkyl) disulfides $\mathbf{1}$ and $\mathbf{2}$ are stable at temperatures of $80^{\circ} \mathrm{C}$ for prolonged annealing times (longer than $24 \mathrm{~h}$ ). Prol onged heating at $100{ }^{\circ} \mathrm{C}$ or heating at temperatures above 100 ${ }^{\circ} \mathrm{C}$ leads to the destruction of the SAM. The SAMs obtained from the symmetrical bis(fluoroalkyl)disulfides 4-6 show different thermal stabilities and thus reflect the different activation of the ester bond toward hydrolysis. ${ }^{29}$ Whereas the contact angles of SAMs of $\mathbf{4}$ decrease at temperatures bel ow $80^{\circ} \mathrm{C}$, the SAM s of 5 remain stable up to $80{ }^{\circ} \mathrm{C}$ and higher. The reverse order of the ester bond gives even more stability to the SAMs of 6 . Intermediate stability is observed for SAMs of the perfluorinated thiol 21.

In Tables 2-4 the contact angles of freshly prepared and subsequently annealed SAM s of mixed di sulfides are summarized. Onecan observethesametrend as indicated by the symmetrical compounds before. The SAMs of the amides, e.g., 18, are stable at $80^{\circ} \mathrm{C}$, whereas at approximately $90^{\circ} \mathrm{C}$ desorption or some unknown reaction leads to slow disintegration of the SAM. Monolayers of the activated $\alpha$-fluoro-substituted esters like those of $\mathbf{9}$ show the poorest thermal stability. The SAMs are destroyed at temperatures as low as $70{ }^{\circ} \mathrm{C}$. Therefore, they will not be considered suitable candidates for the investigation of possible phase separation.

Monolayers of the less activated esters of compounds 13-17 are stable up to $100{ }^{\circ} \mathrm{C}$ for annealing times not Ionger than approximately 10-15 h (Table 4b), although theincreasing hysteresis indicates that monolayers of $\mathbf{1 3}$ are altered by annealing (Table 4a).

For all investigated SAMs we could not observe any dependence of thethermal stability on chain length of the alkyl chain by contact angle measurements or FTIR experiments.

SincetheFTIR measurements in grazing incidencewith perpendicularly polarized light are sensitive to the orientation of the molecules in the SAMs, a comparison of the spectra prior to and after annealing should indicate largescalephaseseparation. 1,30 As demonstrated before, ${ }^{26}$ both alkyl and fluoroalkyl chains are oriented much cl oser to the surface normal direction in the monolayers of the mixed alkyl fluoroalkyl disulfides on gold compared to n-alkanethiols. In contrast, the hydrocarbon chains of the molecules in SAMs of the symmetrical bis(alkyl) disulfides are tilted like those in monolayers of nalkanethiols. For molecules with very long alkyl chains likein $\mathbf{2}$ and $\mathbf{3}$, theall-trans conformation could be proven additionally. ${ }^{26}$

In the process of annealing, the desorption of some of the molecules can be assumed even at lower temperatures. ${ }^{17,18}$ Partly there is still physisorbed material present. Hence the surface coverage is below $100 \%$ for annealed monolayers. If mobility is given and if the mobility results in phase separation into monodomains the alkyl-terminated molecules should be tilted in their domains. These tilted molecules could be detected by means of FTIR.

(29) The activation can be deduced from the $\mathrm{pK}_{\mathrm{a}}$ values of similar partially fluorinated carboxylic acids: $\mathrm{CF}_{3}-\mathrm{COOH} \mathrm{pK}_{\mathrm{a}}=0.26 ; \mathrm{CF}_{3}-$ $\mathrm{CH}_{2}-\mathrm{COOH} \mathrm{pK}_{\mathrm{a}}=3.00 ; \mathrm{CF}_{3}-\mathrm{CH}_{2}-\mathrm{CH}_{2}-\mathrm{COOH} \mathrm{pK}_{\mathrm{a}}=4.15 ; \mathrm{CF}_{3}-$ $\mathrm{CH}_{2}-\mathrm{CH}_{2}-\mathrm{CH}_{2}-\mathrm{COOH} \mathrm{pK}_{\mathrm{a}}=4.49 ; \mathrm{CH}_{3}-\mathrm{CH}_{2}-\mathrm{CH}_{2}-\mathrm{CH}_{2}-\mathrm{COOH} \mathrm{pK}_{\mathrm{a}}$ = 4.81, from: Kissa, E. Fluorinated Surfactants; Marcel Dekker, Inc.: New York, 1994.

(30) Porter, M. D.; Bright, T. B.; Allara, D. L.; Chidsey, C. E. D. J . Am. Chem. Soc. 1987, 109, 3559.

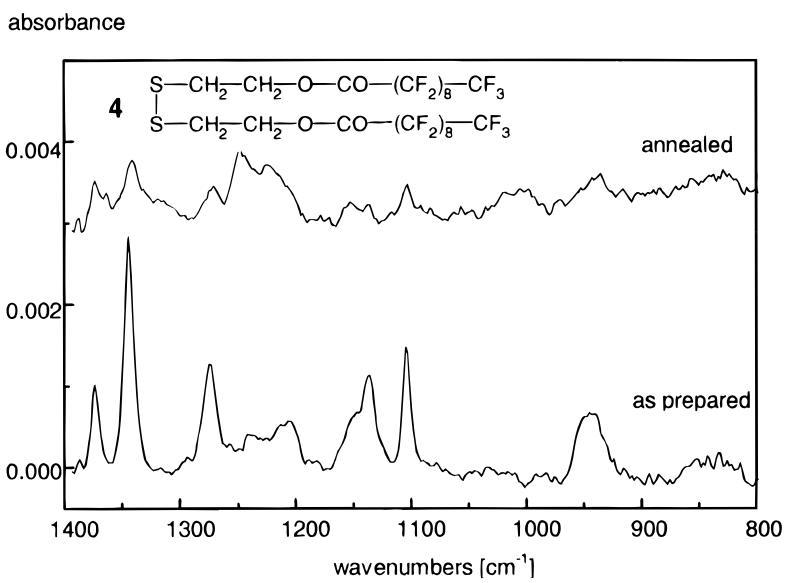

Figure4. FTIR spectra of SAM of $\mathbf{4}$ prior toand after annealing in air for $19 \mathrm{~h}$ at $80^{\circ} \mathrm{C}$.

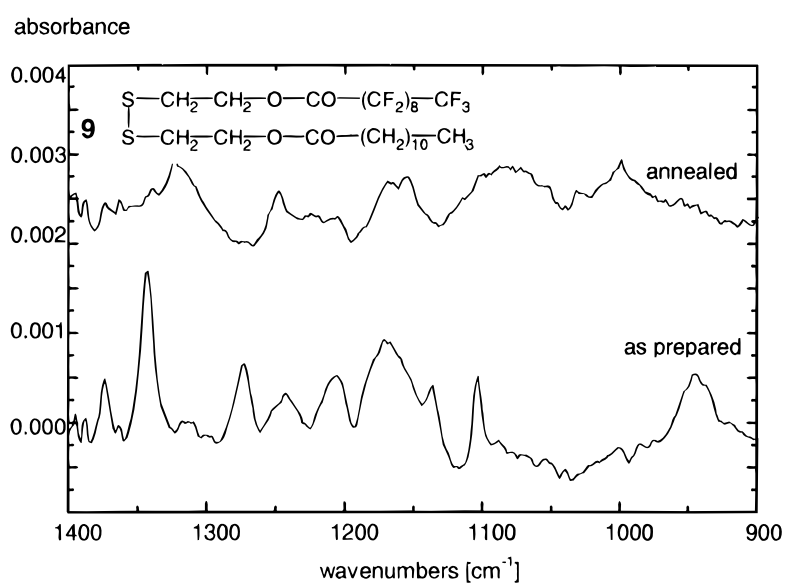

Figure 5. FTIR spectra of SAM of $\mathbf{9}$ prior toand after annealing in air for $36 \mathrm{~h}$ at $100{ }^{\circ} \mathrm{C}$.

In general, the results obtained by FTIR back up the interpretation of the contact angle measurements. The loss of perfluorinated chains in annealed SAMs of the $\alpha$-fluoro-substituted esters in both symmetric and mixed systems can beconfirmed; seeFigures 4 and 5 . Thetypical $\mathrm{C}-\mathrm{F}$ stretching frequencies at about 1375 and $1335 \mathrm{~cm}^{-1}$ are drastically reduced. ${ }^{26}$ As there are no new bands appearing that can be attributed to perpendicular polarized $\mathrm{C}-\mathrm{F}$ stretching vibrations, the loss of the chains has to be assumed.

The formation of large scale phase-separated domains seems to be very unlikely as there is no indication at all for pronounced $\mathrm{C}-\mathrm{H}$ stretching vibrations in any monolayer after nondestructive annealing. ${ }^{31}$ F or monolayers of the $\alpha$-fluoro substituted esters, prolonged annealing, which is accompanied by theloss of thefluorinated chains, leads to observable $\mathrm{C}-\mathrm{H}$ stretching vibrations (absorbance in the order of $1 \times 10^{-3}$ ). We interpret this as the manifestation of additional degrees of freedom of the remaining alkyl chains after the complete loss of the fluorinated ones. 32

The absence of large scale phase separation can also be observed for monolayers obtained from coadsorptions of dodecanethiol and the perfluorinated thiol 21. Annealed monolayers of coadsor ptions from solutions containing the two thiols in ratios of 1:1, 1:3 and 3:1 $\left(3.0 \times 10^{-4} \mathrm{M}\right.$ total concentration $)^{26}$ did not show any evidence for tilted dodecyl thiolate domains. For other systems phase

(31) "N ondestructive annealing" defines the conditions of annealing without excessive loss of fluorinated chains which is detected by decreasing contact angles. 

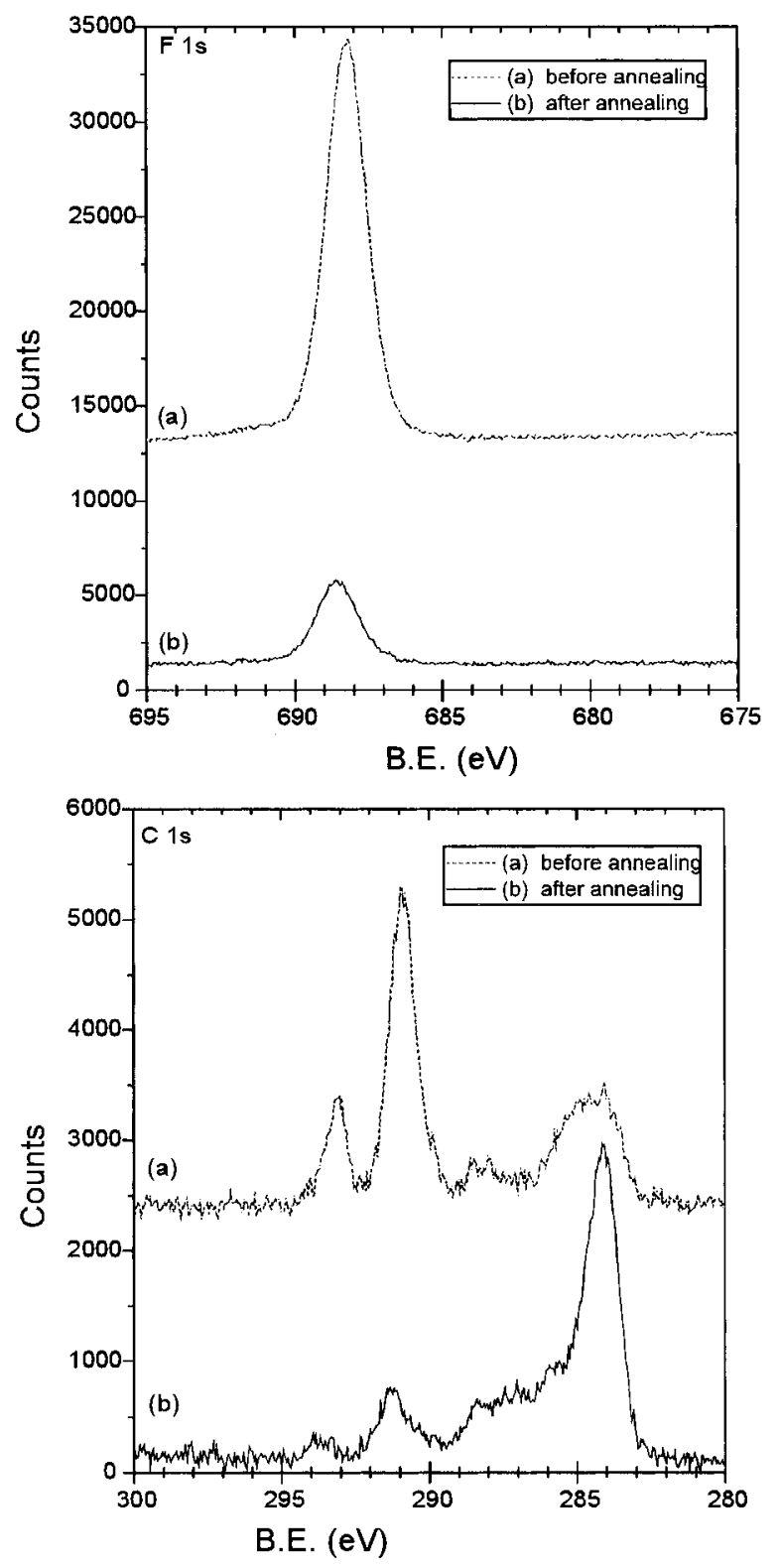

Figure 6. $\mathrm{F}(1 \mathrm{~s})$ and $\mathrm{C}(1 \mathrm{~s}) \mathrm{XPS}$ spectra of SAM of 5 before (curves a) and after (curves b) annealing for $10 \mathrm{~h}$ at $80^{\circ} \mathrm{C}$.

separation has been reported. 33 We assume that our system has a substantially bigger driving force of the molecules to assemble in metastable patches. ${ }^{25}$ The molecular structure of the coadsorbed layers of $\mathbf{2 1}$ and dodecanethiol is thereforepresently investigated by AFM.

XPS measurements were made on monolayers of $\mathbf{1}, \mathbf{5}$, and $\mathbf{1 3}$, both before and after annealing for $10 \mathrm{~h}$ at $80^{\circ} \mathrm{C}$ in air. Figure 6 shows the $\mathrm{F}(1 \mathrm{~s})$ and $\mathrm{C}(1 \mathrm{~s})$ regions for monolayers of $\mathbf{5}$ (a) before annealing and (b) after annealing. These spectral regions contain several points of note. Firstly, considering the C(1s) spectra, in the unannealed sample we can see toward lower binding

(32) This also backs up the hypothesis of the hydrolytic cleavage of the $\alpha$-fluoro-substituted esters in the monol ayers. The annealed SAMs of mixed al kyl fluoroal kyl disul fides can further becompared to annealed SAMs of 2-(n-alkanoyloxy)ethyl 2'-hydroxyethyl disulfide, $\mathrm{HO}-\mathrm{CH}_{2}-$ $\mathrm{CH}_{2}-\mathrm{S}-\mathrm{S}-\mathrm{CH}_{2}-\mathrm{CH}_{2}-\mathrm{O}-\mathrm{CO}-\left(\mathrm{CH}_{2}\right)_{n}-\mathrm{CH}_{3}$, the precursor molecule to the mixed disulfides. ${ }^{26}$ These monolayers show comparable absorbances for the $\mathrm{C}-\mathrm{H}$ stretching vibrations. When annealing SAMs of 2-(n-alkanoyloxy)ethyl 2'-hydroxyethyl disulfide the contact angles increase, eg., the advancing contact angle $\theta_{a}$ of a SAM of 2-(ndodecanoyloxy)ethyl $2^{\prime}$-hydroxyethyl disulfideincreases from $95^{\circ}$ to $102^{\circ}$ after annealing at $70^{\circ} \mathrm{C}$ for $40 \mathrm{~h}$.

(33) Stranick, S. J .; Parikh, A. N.; Tao, Y.-T.; Allara, D. L.; Weiss, P. S. J. Phys. Chem. 1994, 98, 7636.
Table 5. Changes in the $O(1 s)$ and $F(1 s)$ XPS Signals of Different SAMs upon Annealing for $10 \mathrm{~h}$ at $80^{\circ} \mathrm{C}$, Measured with Respect to the Total Carbon Content within the Monolayers

\begin{tabular}{cll}
\hline sample & O/C & F/C \\
\hline $\mathbf{5}$ not annealed & 0.29 & 6.68 \\
$\mathbf{5}$ annealed & 0.80 & 1.38 \\
$\mathbf{1}$ not annealed & 0.61 & 0 \\
$\mathbf{1}$ annealed & 0.52 & 0 \\
$\mathbf{1 3}$ not annealed & 0.75 & 3.82 \\
$\mathbf{1 3}$ annealed & 2.06 & 1.71
\end{tabular}

energy the peaks associated with the alkyl $\left(\mathrm{CH}_{2}\right)$ units at ca. $284 \mathrm{eV}$. The peak is broad and has several contributions, seen as a shoulder toward thehigh energy side; this is due to the differing nature of the carbons within this molecule. From chemical structure considerations wesee that each of the carbons in the lower alkyl chain is unique in terms of its local bonding; thus each gives a slightly different contribution tothetotal carbon signal. TheC(1s) peaks associated with the $\mathrm{CF}_{2}$ and $\mathrm{CF}_{3}$ groups occur at much higher binding energies, 291 and $293 \mathrm{eV}$, respectively, and are thus easily distinguished from the lower carbon portions. Upon annealing, curve $b$, we see $a$ dramatic change in the C(1s) spectra; in particular wesee that there is a considerable loss in the perfluoroalkyl carbon signal. Associated with this decrease wefind that the relative intensity of the lower alkyl groups increases, as one would expect since there is now less attenuation due to the removal of the fluorocarbon chains. The loss of fluorcarbon is also clearly seen by the decrease of the $F(1 s)$ signal following annealing. Finally, we note that the signal due to the oxygen $(\mathrm{O}(1 \mathrm{~s}))$ increases upon annealing; this is also consistent with our explanation since these groups would now be very cl ose to the surface and hence not attenuated.

Table 5 presents the results for mol ecules $\mathbf{1 , 5}$, and $\mathbf{1 3}$. In each case we present the ratio of the signal of a given species to the total carbon signal. This permits a qualitative discussion of changes occurring due to the anneal ing process. If "whole" molecules were being lost during the annealing and if the remaining molecules formed ordered domains, this ratio would be constant. We would expect slight changes if they tended toward a disordered state. It is apparent that in all cases the ratio of fluorine to carbon present in the film decreases significantly on annealing. It is thus more likely to be related to the cleavage of the mol ecules. The decrease in the $\mathrm{F} / \mathrm{C}$ ratio is associated with an increase in the $\mathrm{O} / \mathrm{C}$ ratio, which may be accounted for by the reduction of attenuation due to the loss of the overlying fluoroalkyl portion of the molecule. Monolayers of $\mathbf{1}$, dial kyl disulfide, showed much smaller changes upon anneal ing and suggest that thealkyl-substituted derivatives aremorestablethan thosecontaining thefluoroalkyl derivatives. Theseresults arethus in general agreement with thewetting and FTI R data and are consistent with the picture proposed here of the loss of the fluoralkyl chains through hydrolytic cl eavage. ${ }^{34}$

The most convincing proof for the absence of phase separation in annealed monolayers of $\mathbf{1 3}$ on gold(111) is obtained from AFM data. We investigated only SAMs of compound 13 because of several reasons.

The visualization of the two-dimensional lattice of freshly prepared SAMs could be achieved previously together with the corresponding symmetrical systems. ${ }^{23}$ Since the disulfide contains two chains of equal length,

(34) The reaction does not proceed in bulk material annealed in air at similar conditions as can be proven by ${ }^{1} \mathrm{H}-\mathrm{N}$ M R spectroscopy. Hence it seems to be an interfacial reaction. 
Table 6. AFM Results on Freshly Prepared SAMs of Different Disulfides on Au(111) ${ }^{23}$

\begin{tabular}{cc}
\hline compound & $\begin{array}{c}\text { lattice constant of the } \\
\text { hexagonal lattice, } \AA\end{array}$ \\
\hline $\mathbf{1}$ & 5.28 \\
$\mathbf{2}$ & $5.27^{\mathrm{a}}$ \\
$\mathbf{5}$ & 5.87 \\
$\mathbf{1 3}$ & 6.20
\end{tabular}

a For compound $\mathbf{2}$ a second lattice of centered rectangular symmetry is found.

Table 7. AFM Results on Annealed SAMs of Compound 13 on Au (111)

\begin{tabular}{cl}
\hline $\begin{array}{c}\text { annealing } \\
\text { conditions }\end{array}$ & \multicolumn{1}{c}{ observed monolayer structure } \\
\hline $1 \mathrm{~h}, 60^{\circ} \mathrm{C}$ & domains with hexagonal lattice, $\mathrm{d}=6.2 \AA$ \\
$8 \mathrm{~h}, 75^{\circ} \mathrm{C}$ & domains with hexagonal lattice, $\mathrm{d}=6.2 \AA$ \\
$16 \mathrm{~h}, 90^{\circ} \mathrm{C}$ & domains with hexagonal lattice, $\mathrm{d}=6.2 \AA$ \\
$48 \mathrm{~h}, 90^{\circ} \mathrm{C}$ & no ordered monolayer structure \\
$17 \mathrm{~h}, 100^{\circ} \mathrm{C}$ & domains with hexagonal lattice, $\mathrm{d}=6.2 \AA$ \\
$65 \mathrm{~h}, 110^{\circ} \mathrm{C}$ & no ordered monolayer structure
\end{tabular}

the surface of the monolayer is easier to image with AFM than disul fides with different chain lengths. In the AFM images obtained the chain ends are visualized; thelattice formed by both $-\mathrm{CH}_{3}$ and $-\mathrm{CF}_{3}$ groups is recognized. The observed lattice constants of thehexagonal lattices formed by freshly prepared SAM s arelisted in Table6. I mportant is the unique lattice that is formed by $\mathbf{1 3}$. The lattice constant of the hexagonal lattice is bigger than thelattice constants of both the symmetrical bis(alkyl) and the bis(fluoroalkyl)disulfide. Furthermore, thesymmetrical bis(alkyl)disulfide forms two lattices of different symmetry. Thus, if phase separation occurs, three additional lattice constants shoul d be detected: One for the perfluorinated part and two for the alkyl part.

The linkage of the partly fluorinated chain to the disulfide with an ethyl bridge is the most stable of the three homologous series investigated in this study. Ther eforeannealing at temperatures closetothethreshold for desorption $\left(100^{\circ} \mathrm{C}\right)$ is still possible and investigation by AFM should beableto detect theappearance of different periodicities.

The freshly prepared monol ayers were annealed in air at temperatures ranging from 60 to $110^{\circ} \mathrm{C}$ for different times (see Table 7). After cooling down to room temperature the substrates were put into the liquid cell of the AFM filled with ethanol and were imaged immediately. Figures 7-9 show AFM scans of a freshly prepared and two differently annealed SAMs of $\mathbf{1 3}$ on gold(111) in molecular resolution. Domains in which the packing is good arestill frequentl y observed. The packing distances of the hexagonal lattice remains $6.2 \AA$; no additional periodicity can be detected in the two-dimensional fast Fourier transforms of the data evaluation procedure. ${ }^{23,28}$ Annealing for very long times at temperatures of $110^{\circ} \mathrm{C}$ destroys all order in the organic monolayer that can be imaged by AFM. Desorption and hydrolysis of the esters are probably too pronounced under these conditions. As can be seen from the unchanged packing distances for annealed SAM s of 13 (anneal ing at $100^{\circ} \mathrm{C}$ for $17 \mathrm{~h}$ ) phase separation can be excluded for these systems under the conditions used.

The absence of phase separation in the investigated SAMs of mixed alkyl fluoroalkyl disulfides can be attributed to various reasons. These can be discussed in a speculative way only because the underlying processes are up to now not well understood. We suppose that the mobility of molecules within the monolayer is probably only pronounced at defect sites likevacancies in thelattice

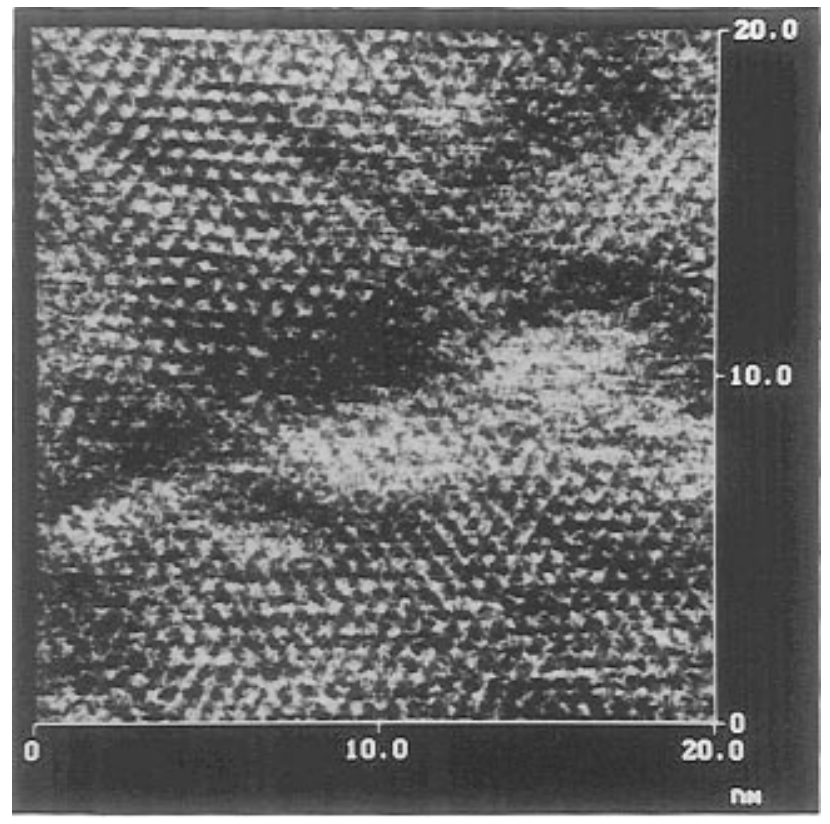

Figure 7. AFM image of a freshly prepared SAM of $\mathbf{1 3}$ on gold(111) taken in ethanol. In the middle a domain boundary is visible, in the lower right and the upper left part of the image thehexagonal lattice formed by the $-\mathrm{CH}_{3}$ and the $-\mathrm{CF}_{3}$ groups can be seen.

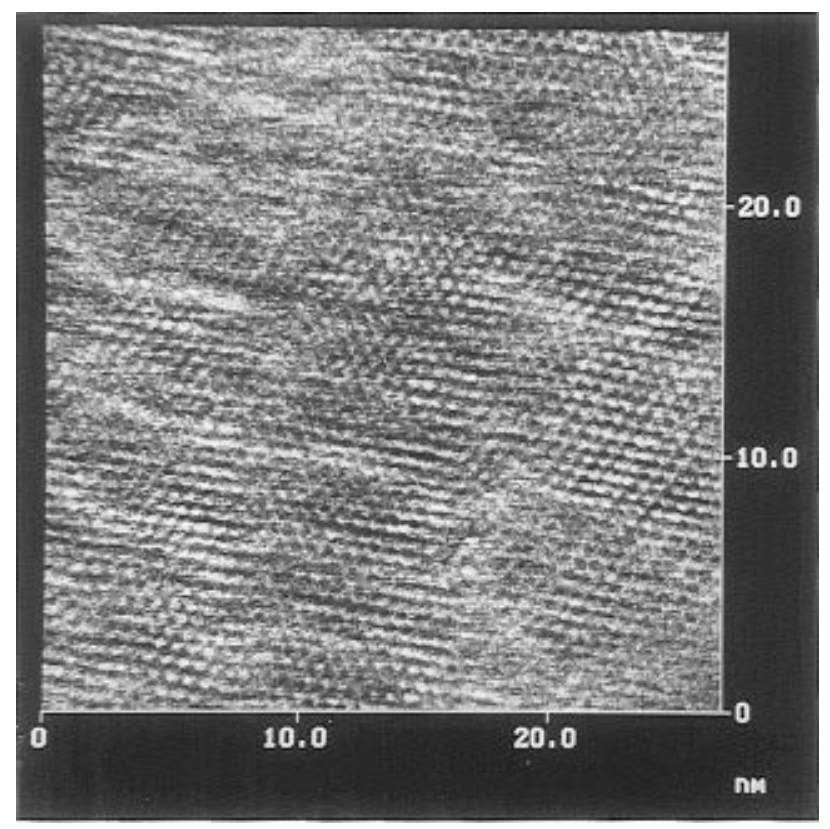

Figure 8. $A F M$ image of an annealed $S A M$ of $\mathbf{1 3}$ on gold(111). The monolayer was annealed for $16 \mathrm{~h}$ at $90{ }^{\circ} \mathrm{C}$ in air. The hexagonal lattice of themixed disulfide $(d=6.2 \AA)$ is recognized inside well-ordered domains.

of the organic material. The mobility of the gold atoms in thetop layer is known. ${ }^{20}$ Theintroduction of alkyl and perfluoroalkyl substituents should lower the interaction between unlike chains in the truely mixed system one obtains by the assembly of mixed disulfides. Hence, this should speed up the rate of diffusion of the gold atoms as has been observed for sulfur and chlorine. ${ }^{35}$ On the other hand mobility of thiolates was assumed on the basis of STM investigations. ${ }^{17 a, 20}$ Herethe mobility of the defects in the gold has been observed in the first place. Mobility of thiolates or disulfides cannot be excluded at the edges

(35) (a) Trevor, D. J .; Chidsey, C. E. D.; Loiacono, D. N. Phys. Rev. Lett. 1989, 62, 929. (b) Trevor, D. J .; Chidsey, C. E. D. J . Vac. Sci. Technol. B 1991, 9, 964. 


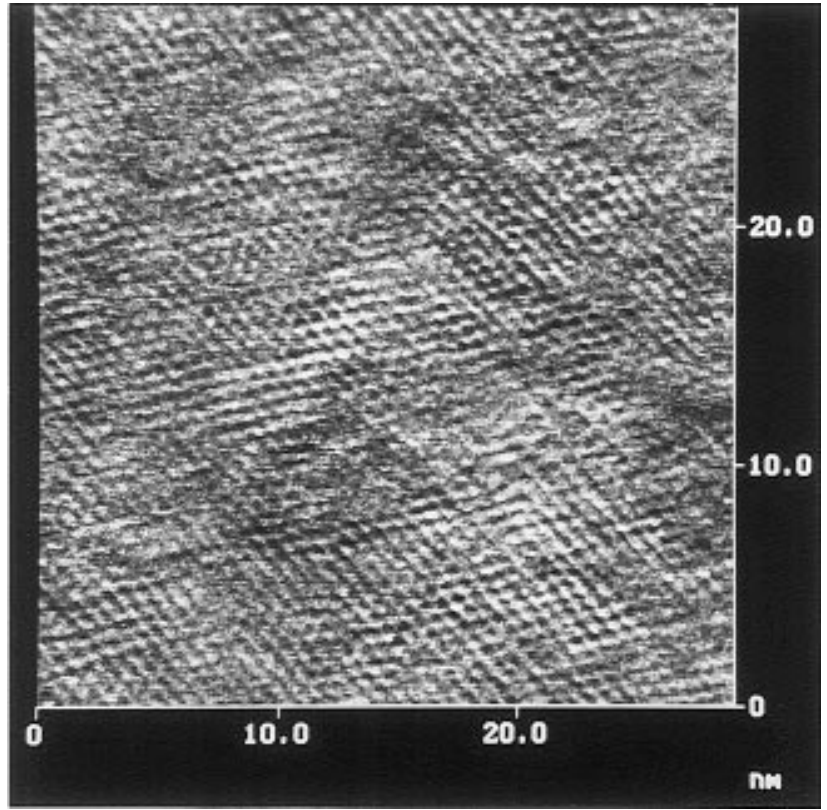

Figure 9. AFM image of an annealed SAM of $\mathbf{1 3}$ on gold(111). Although the XPS data show a significant loss of fluorine and hencefluoroalkyl chains in anneal ed monolayers, thehexagonal lattice of the mixed disulfide $(d=6.2 \AA)$ is still recognized insi de well ordered domains after annealing for $17 \mathrm{~h}$ at $100^{\circ} \mathrm{C}$ in air. No monodomains of alkyl or fluoroalkyl chains can be detected.

of the terraces and etch pits. But these areas probably do not represent the interior of the densely packed layer.

In order to further increase the rate of diffusion one runs into the problem of desorption at temperatures around $100{ }^{\circ} \mathrm{C}$. In conclusion, either the mobility does not exist in the interior of the layer or else the rate of diffusion is far too small to be detected, leave al one to be of any use in a patterning as briefly discussed in the introduction.

A second possible explanation could be the recent postulation of disulfides as the molecular species bound to the gold. ${ }^{16}$ If there was no cleavage of the sulfursulfur bond in the mixed alkyl fluoroalkyl disulfides investigated in this study, a phase separation would not be expected provided that the disulfide bond remained intact under the annealing conditions applied.

Unfortunately, weare not ableto discriminate between the two plausibleexplanations on the basis of our results. A new approach could for instance include the investigation of similar, but thermally more stable, SAMs. First, the linkage between sulfur functionality and the perfluorinated chain should be only an alkyl segment. Second, thealkyl chain could befunctional ized by someazobenzene moiety in $\omega$-position ${ }^{36}$ that enhances thermal stability and the attractive interaction between alike molecules.

\section{Conclusions}

The thermal stability of a large number of SAMs of symmetrical and mixed alkyl fluoroalkyl disulfides has been investigated by a multipronged approach including contact angle, grazing incidence FTIR, XPS, and AFM measurements. The limited thermal stability of the molecules in the SAMs in air stems on one hand from the different linkage of the perfluorinated chain to thesulfur containing functional group on the other hand from the inherent desorption of thiols and disulfides at temperatures of $100^{\circ} \mathrm{C}$ and higher. The $\alpha$-fluoro-substituted esters arehydrolyzed at $60-70^{\circ} \mathrm{C}$, the ami de-based systems are stable up to approximately $90{ }^{\circ} \mathrm{C}$ and the $\gamma$-fluorosubstituted esters are stable up to $100{ }^{\circ} \mathrm{C}$ provided annealing times are not longer than $10 \mathrm{~h}$. The FTIR and AFM experiments do not give any evidence for heatinduced phase separation. There are no tilted alkyl domains detectablein theFTIR, and theuniquehexagonal lattice of the mixed alkyl fluoroalkyl disulfides remains unchanged even after annealing for $17 \mathrm{~h}$ at $100^{\circ} \mathrm{C}$ in air, as confirmed by AFM. The observed behavior can be attributed to nonexisting or very low mobility of molecules in tighly packed SAMs. Alternatively, it cannot be ruled out that disulfides instead of thiolates are bound to the gold substrate.

\section{LA9601420}

(36) SAMs of azobenzenethiols ${ }^{28}$ on $A u(111)$ were found to be thermally even more stable than n-alkanethiols. With AFM the periodicity can be still observed for SAMs annealed at $120^{\circ} \mathrm{C}$ in air. This is probably due to increased interaction of the aromatic cores compared to the alkyl chains of simple n-alkanethiols. 